\title{
Mean level signal crossing rate for an arbitrary stochastic process: reply to comment
}

\section{Yura, Harold; Hanson, Steen Grüner}

\section{Published in:}

Optical Society of America. Journal A: Optics, Image Science, and Vision

Link to article, DOI:

10.1364/JOSAA.29.000167

Publication date:

2012

Document Version

Publisher's PDF, also known as Version of record

Link back to DTU Orbit

Citation (APA):

Yura, H., \& Hanson, S. G. (2012). Mean level signal crossing rate for an arbitrary stochastic process: reply to comment. Optical Society of America. Journal A: Optics, Image Science, and Vision, 29(2), 167-168.

https://doi.org/10.1364/JOSAA.29.000167

\section{General rights}

Copyright and moral rights for the publications made accessible in the public portal are retained by the authors and/or other copyright owners and it is a condition of accessing publications that users recognise and abide by the legal requirements associated with these rights.

- Users may download and print one copy of any publication from the public portal for the purpose of private study or research.

- You may not further distribute the material or use it for any profit-making activity or commercial gain

- You may freely distribute the URL identifying the publication in the public portal 


\title{
Mean level signal crossing rate for an arbitrary stochastic process: reply to comment
}

\author{
Harold T. Yura ${ }^{1}$ and Steen G. Hanson ${ }^{2, *}$ \\ ${ }^{1}$ Electronics and Photonics Laboratory, The Aerospace Corporation, Los Angeles, California 90009, USA \\ ${ }^{2}$ DTU Fotonik, Department of Photonics Engineering, Danish Technical University, 4000 Roskilde, Denmark \\ *Corresponding author: Steen.Hanson@fotonik.dtu.dk \\ Received October 19, 2011; revised November 3, 2011; accepted November 4, 2011; \\ posted November 4, 2011 (Doc. ID 156820); published January 9, 2012 \\ (C) 2012 Optical Society of America \\ OCIS codes: $\quad 030.1640,120.7250,030.1670,030.6140,030.6600$.
}

In a comment by Santos Filho et al. [1] some comments and concerns regarding a recent article [2] have been raised. In this article we addressed the issue of finding an engineering approach to the average number of level crossings for a signal with an arbitrary probability density function (PDF) for its signal level. This article was based on the seminal work by Rice [3] in the 1940s. The authors of the above comment have concurrently published an article on the second-order statistics of Nakagami fading simulators [4]. The details for arriving at the results for the average number of level crossings and thus the average time for a surge and a fade can be found in the articles but will here be recapped in short. Our approach [2] was based on a nonlinear, memoryless transformation of the PDF under investigation into a zero-mean, unit variance Gaussian PDF from which we know the number of level crossings [3]. The transformation being bijective, and knowing that the correlation between the signal and its first derivative is zero, the signal and its first derivative were considered independent. We showed that one could in many cases obtain sufficient agreement between the analytical results and the results arrived at by simulations. As stated in the article, for some PDFs-especially Nakagami distributions with low order (exponential and Rayleigh distributions)-we observed a discrepancy. Here, the authors of this comment have in a good way addressed our concern in [2], where we "laid open future discussion" of this discrepancy. And we agree on their explanation for this discrepancy for these distributions, and thank them for their effort.

The authors have in [4] (Ref. 4 in the comment) addressed the problem focusing only on the Nakagami envelope. Their approach-named the "nonclassical" approach-is in many aspects similar to ours, the only change being the transformation into a Rayleigh distribution where the average number of level crossings is known, as it is for the Gaussian distribution. The resulting LCR was compared to Nakagami's "classical" LCR (which is analogous to the sum of squares method discussed in [1]) in Eqs. (6) and (15), as well Fig. 3 of [4], where it is only seen that the classical and nonclassical LCRs do not agree. Physically, there is one and only one correct result for the LCR of the Nakagami process (as well as for all other physical stochastic processes), and the authors do not relate to the reader any information regarding the correct LCR. Because no experimental data were presented, the reader has no clue to which of the two LCRs is the correct one for the Nakagami distribution. In this regard, we note that in [5] comparison of theoretical results with measured data revealed that the classical Nakagami, the Rice, and even the simple Rayleigh model show reasonable fits in terms of LCR and average fade duration for most of the records, independent of the cumulative distribution fits.

In the comment, the authors purport to present a formal general solution that is applicable to arbitrary random processes. This solution is based on finding a suitable input PDF into which the arbitrary PDF under consideration has to be transformed. The authors do not specify how to arrive at this input (seed) signal $X(t)$ but claim without justification that "the resulting higher-order statistics of $Y(t)$ describe well the real physical phenomena involved with the process under investigation." Additionally, in order to correctly obtain the corresponding LCR, one needs to know the LCR of the (unspecified) input "seed" $X(t)$. Therefore, a quantitative roadmap for obtaining the correct expression for the LCR of an arbitrary stochastic process has not been given. In particular, it is claimed that "our formula (6) already presented in [4], is a general solution that gives the LCR of $Y(t)$ in terms of the LCR of $X(t)$, applicable to arbitrary random processes and fully consistent with the Rice formula in all of the cases." We respectfully note that in [4] of the comment, only the Nakagami envelope distribution is considered and that in fact the authors show the discrepancy between the so-called classical and nonclassical method. Thus, in view of the lack of experimental evidence as to whether the classical or nonclassical LCRs are valid, Eq. (6) of the comment cannot be considered a result that is fully consistent with Rice's formula for all cases. For example, the devised "nonclassical" method, unfortunately, will especially give large discrepancies if used on PDFs such as a uniform, a beta, or a LaPlace distribution.

In conclusion, we thank the authors for pinpointing the origin of the discrepancy we reported with our method. At the same time, we argue that this interesting issue still needs 
further investigation in order to arrive at analytical results for level crossing rates, average time of fades and surges, for arbitrary PDFs. The two methods as alluded to in [2] and the comment both have shortcomings and should-as argued here-be considered as engineering approaches to the problem.

\section{REFERENCES}

1. J. C. S. Santos Filhos, M. D. Yacoub, and G. K. Karagiannidis, "Mean level signal crossing rate for an arbitrary stochastic process: comment," J. Opt. Soc. Am. A 29, A41-A43 (2012).
2. H. T. Yura and S. G. Hanson, "Mean level signal crossing rate for an arbitrary stochastic process," J. Opt. Soc. Am. A 27, 797-807 (2010).

3. S. O. Rice, "Mathematical analysis of random noise," in Selected Papers on Noise and Stochastic Processes (Dover, 1954).

4. J. C. S. Santos Filho and M. D. Yacoub, "On the second-order statistics of Nakagami fading simulators," IEEE Trans. Commun. 57, 3543-3546 (2009).

5. A. Abdi, K. Wills, H. A. Barger, M.-S. Alouini, and M. Kaveh, "Comparison of the level crossing rate and average fade duration of Rayleigh, Rice, and Nakagami fading models with mobile channel data," in Proceedings of VTC (2000), pp. 1850-1857. 